\title{
Thyrotoxicosis and lactate-producing angina pectoris with normal coronary arteries
}

\author{
LEON RESNEKOV AND RAUL E. FALICOV
}

From the Department of Medicine, Section of Cardiology, The University of Chicago, Pritzker School of Medicine, Chicago, Illinois, U.S.A.

Three patients with thyrotoxicosis are described, in whom the presenting symptom was severe cardiac pain at rest or on effort and who were admitted to hospital with suspected or proven myocardial infarction. All patients were studied by selective coronary arteriography and left ventriculography after thyroid function tests which confirmed thyrotoxicosis. There was no demonstrable disease of the major coronary arteries in any of the patients, yet myocardial infarction and left ventricular aneurysm were shown to be present in 1, and there was definite electrocardiographic evidence of ischaemia in all 3. In addition, under stress the myocardium of all 3 patients produced lactate. It is recommended that thyrotoxicosis be seriously considered in the differential diagnosis of cardiac pain, particularly in younger women. The cause of the pain seems related to the cellular effects of thyrotoxicosis on the myocardium and current views of these effects are summarised. Of the 3 patients, 1 died suddenly 6 months after becoming euthyroid, indicating that the disease may not be as benign as expected. A guarded prognosis and continued medical follow-up are recommended when thyrotoxicosis presents with angina pectoris even when normal coronary arteries have been demonstrated.

Coronary arterial disease remains the single most important cause of cardiac pain. Angina pectoris may be mimicked, however, by disease processes affecting the myocardium not a result of diffuse or obstructive lesions of the coronary arteries. Having recently investigated 3 patients admitted to hospital with myocardial infarction or unstable angina pectoris, in all of whom thyrotoxicosis was present, we wish to draw attention to thyrotoxicosis as a cause of cardiac pain, particularly in younger adult women. Selective coronary arteriography excluded epicardial coronary arterial disease as a cause but myocardial lactate production was elicited by the stress of provoked tachycardia and/or afterload elevation, strongly suggesting myocardial cellular hypoxia as the origin of their presenting symptoms.

\section{Methods of study}

Cinecoronary arteriography was performed by the Judkins (1967) technique and multiple oblique projections obtained after selective injections in each coronary ostium. Simultaneous blood samples from the coronary sinus and a systemic artery were obtained in duplicate in each of the following states: (i) control; (ii) right ventricular pacing at a rate of Received for publication 27 September 1976
130 a minute for 3 minutes; (iii) right ventricular pacing at a rate of 150 a minute; (iv) control; (v) phenylephrine infusion $(20 \mathrm{mg} / 500 \mathrm{ml})$ intravenously at rates sufficient to raise the systolic blood pressure by 30 to $40 \mathrm{mmHg}$ for 3 minutes; (vi) ventricular pacing at a rate of 130 a minute while phenylephrine infusion was continued for 3 minutes; (vii) final control. In 1 patient (case 2) ventricular pacing only was performed.

Plasma lactate was analysed by the technique of Vaughan and Galloway (1964). Lactate extraction (production), expressed as a percentage, was calculated from the formula:

$$
\left[(\mathrm{A}-\mathrm{V}) \times \mathrm{A}^{-1} \times 100\right] \%
$$

where: $A$ and $V$ represent arterial and coronary sinus blood plasma concentration of lactate, respectively.

Normal lactate extraction is considered to be more than 10 per cent. Lactate extraction of less than 10 per cent or any degree of lactate production (negative ratio) is considered to be biochemical evidence of myocardial ischaemia.

Selective left ventriculography in two planes was also obtained and the films analysed for abnormalities of ventricular function and contraction. Left ventricular and aortic pressures were recorded. 


\section{Patients studied}

\section{CASE 1}

A 37-year-old woman was admitted to the coronary care unit with a diagnosis of acute myocardial infarction. Typical angina pectoris associated with shortness of breath and diaphoresis occurred before admission to hospital. Initially in sinus rhythm, atrial fibrillation supervened but the ventricular rate was difficult to control with digoxin. Serial electrocardiograms indicated anteroseptal infarction with persistent elevation of ST segments, suggesting ventricular aneurysm (Fig. 1). There were no obvious clinical signs of thyrotoxicosis and a goitre was not felt. Thyroid function tests were nevertheless grossly abnormal with a free thyroxine index (FTI) of $18.0 \mu \mathrm{g} / 100 \mathrm{ml}(232 \mathrm{nmol} / \mathrm{l})$ and a total thyroxine level $\left(\mathrm{TT}_{4}\right)$ of $20 \cdot 2 \mu \mathrm{g} / 100 \mathrm{ml}(260 \mathrm{nmol} / \mathrm{l})$. Upper normal limits in our laboratory for these tests are FTI $9.3 \mu \mathrm{g} / 100 \mathrm{ml}(120 \mathrm{nmol} / \mathrm{l})$ and $\mathrm{TT}_{4}$ $9.4 \mu \mathrm{g} \mathrm{T}_{4} / 100 \mathrm{ml}(121 \mathrm{nmol} / \mathrm{l})$. Despite bedrest and controlling the ventricular rate with a combination of digoxin $0.5 \mathrm{mg} /$ day and propranolol $160 \mathrm{mg} /$ day, she continued to have angina pectoris on effort. Cardiac catheterisation studies as previously outlined were performed 6 weeks after acute infarction, at a time when the thyrotoxicosis was brought under medical control. Left and right coronary arteries showed no lesions or irregularities of their major branches (Fig. 2C, D). The left ventricular pressure was $160 / 21 \mathrm{mmHg}$. Biplane left ventricular cineangiocardiography in the anteroposterior and lateral projections showed moderate hypertrophy of the left ventricle with pronounced hypokinesis of the anterior wall and a large apical aneurysm (Fig. 2A, B). The remainder of the ventricle contracted well and there was no mitral regurgitation. After left ventriculography, left ventricular pressure rose to $160 / 40 \mathrm{mmHg}$. Immediately after the anatomical study, a myocardial lactate investigation was performed. Though lactate was not produced during the control state, pacing and phenylephrine drug infusion alone and in combination resulted in an abnormal response with lactate production (Fig. 3 and Table). The patient did not experience any angina pectoris during this study. She has continued well since discharge from hospital and is now euthyroid.

\section{CASE 2}

A 40-year-old woman was admitted to the coronary care unit with suspected myocardial infarction because of severe typical angina pectoris which was recurrent and prolonged even at rest. The electrocardiogram indicated a pattern suggesting anterior infarction with added transient ST segment depression during episodes of pain (Fig. 4), but there was no evolution of this pattern nor were sequential serum enzyme levels (CK and LDH) diagnostic of infarction. The thyroid gland was palpably enlarged but there were no clinical signs of thyrotoxicosis. The FTI value was $26.9 \mu \mathrm{g} / 100 \mathrm{ml}$ (346 nmol/l), the $\mathrm{TT}_{4}$ was $19.9 \mu \mathrm{g} / 100 \mathrm{ml}$ (256 nmol/1), and a thyroid scan showed a 24-hour uptake of 51 per cent.

After the thyrotoxicosis had been treated cardiac catheterisation showed a resting left ventricular pressure of $160 / 20 \mathrm{mmHg}$. The left ventriculogram in the anteroposterior and lateral projections was normal and selective coronary arteriography showed normal major epicardial vessels and their branches. A myocardial lactate study indicated that no lactate was produced during control, but there was an abnormal lactate response after the heart rate was
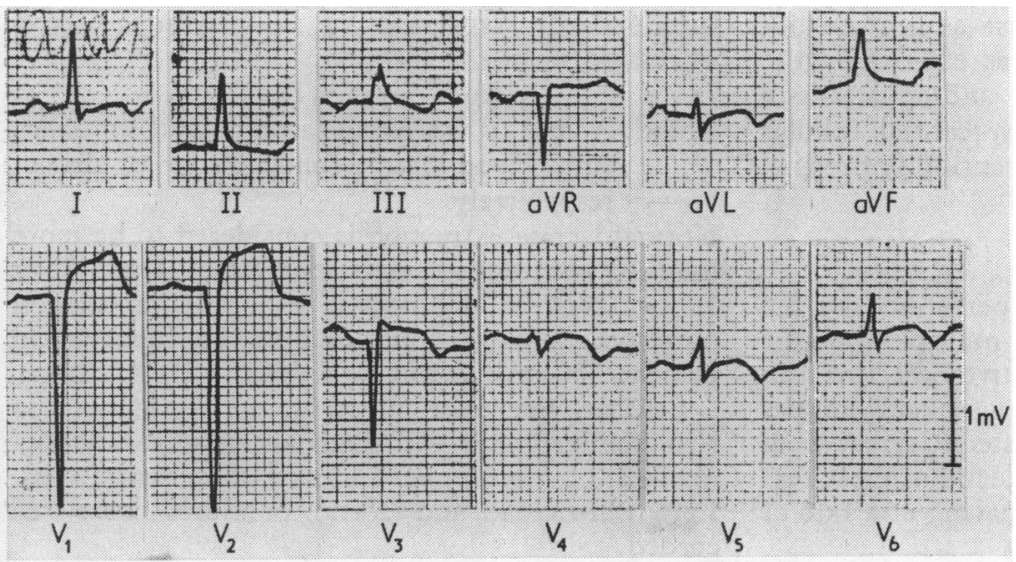

Fig. 1 Electrocardiogram, case 1. Note the pattern of anterior transmural myocardial infarction. The ST segment elevation persisted, suggesting ventricular aneurysm. 


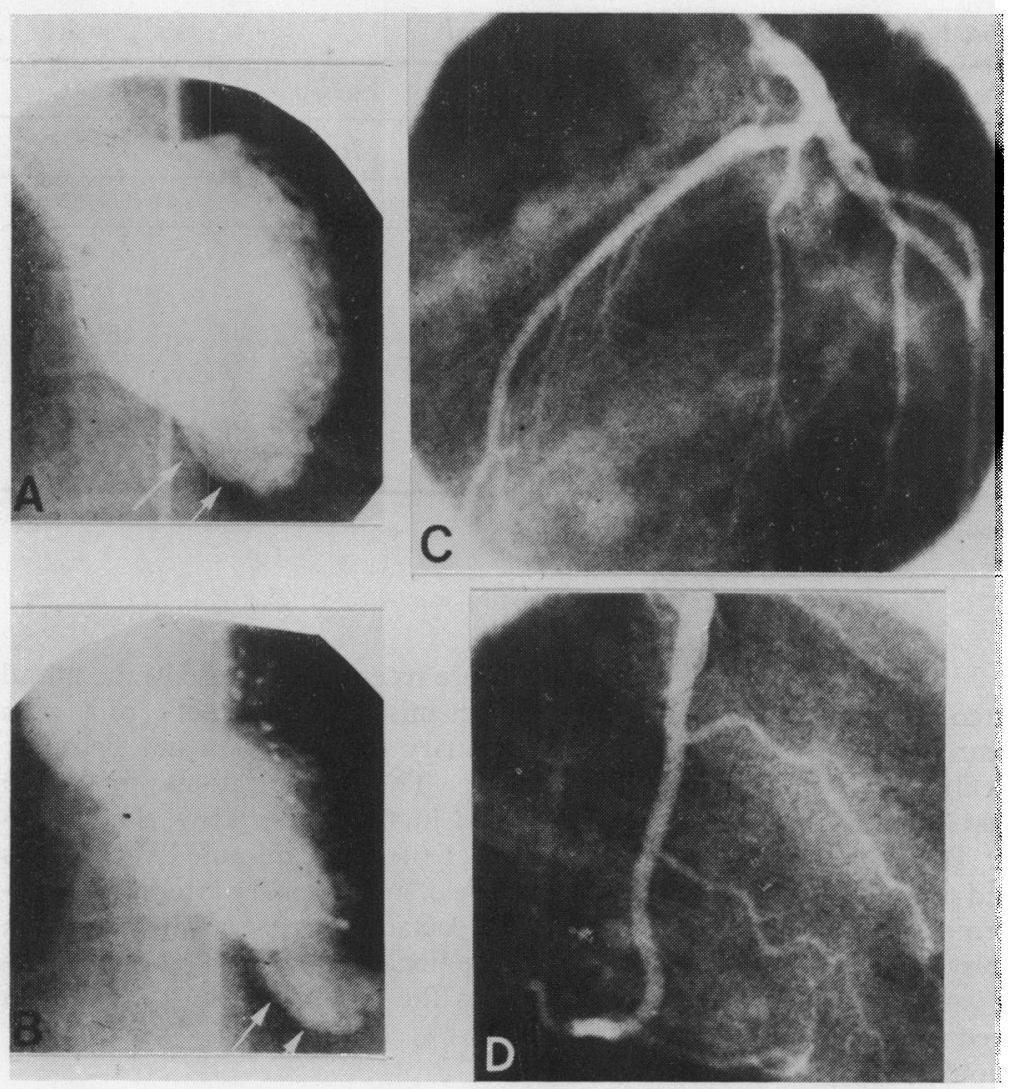

Fig. 2 Left ventriculogram $(A, B)$ and selective coronary arteriogram $(C, D)$, case 1 . (A) diastolic frame, anteroposterior projection; (B) systolic frame, anteroposterior projection; (C) left coronary artery, left anterior oblique projection; (D) right coronary artery, right anterior oblique projection.

In $A$ and $B$ arrows point to the left ventricular aneurysm. Normal left and right coronary arteries are shown in $C$ and $D$.

raised to 150 beats a minute by right ventricular pacing (Table).

The thyrotoxicosis was treated continuously with propylthiouracil $200 \mathrm{mg} 3$ times daily and, in addition, she was given propranolol to a total of $160 \mathrm{mg}$ each day. Subsequently, radioactive iodine was given, after blocking the thyroid gland. Initially, she did well, but 6 months later suddenly collapsed in the street and died. There was no necropsy.

Fig. 3 Myocardial lactate study, case 1. Figures represent the product of heart rate and mean arterial blood pressure (see Table and text). There is lactate production when the myocardium is stressed by increasing the heart rate to $130 /$ minute by right ventricular pacing $(P)$, by increasing the afterload using an intravenous infusion of phenylephrine (PH), or by a combination of these 2 measures ( $P$ and $P H$ ). During control measures (C) there is no lactate production. A control value was also obtained after pacing alone (Table) but has been omitted in this figure for the sake of clarity.

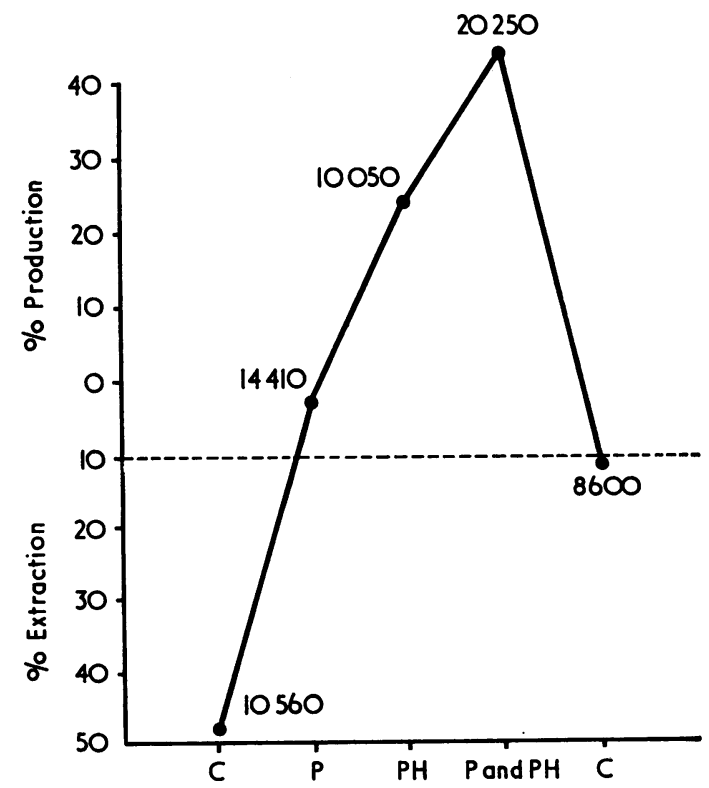


Table Results of myocardial lactate study: lactate production is always abnormal

\begin{tabular}{|c|c|c|c|c|c|c|c|c|c|}
\hline \multirow[t]{3}{*}{ Status } & \multicolumn{3}{|l|}{ Case 1} & \multicolumn{3}{|l|}{ Case 2} & \multicolumn{3}{|l|}{ Case 3} \\
\hline & \multirow[t]{2}{*}{$H R \times \overline{B P} \star$} & \multicolumn{2}{|l|}{ Lactate \% } & \multirow{2}{*}{$-H R \times \overline{B P^{\star}}$} & \multicolumn{2}{|l|}{ Lactate \% } & \multirow{2}{*}{$H R \times \overrightarrow{B P \star}$} & \multicolumn{2}{|l|}{ Lactate $\%$} \\
\hline & & Extraction & Production & & Extraction & Production & & Extraction & Production \\
\hline $\begin{array}{l}\text { Control } 1 \\
\text { Pacingt }\end{array}$ & 10560 & 48 & 0 & 14400 & 15 & 0 & 11250 & 29 & 0 \\
\hline Rate 130 & 14410 & 0 & 3 & 23460 & 19 & 0 & - & - & - \\
\hline Rate 150 & 18600 & 0 & 1 & 29750 & 0 & 28 & 13502 & 13 & 0 \\
\hline Control 2 & 11250 & 14 & 0 & - & - & - & 11760 & 48 & 0 \\
\hline Phenylephrine & 10050 & 0 & 24 & - & - & - & 10080 & 43 & 0 \\
\hline $\begin{array}{l}\text { Phenylephrine and pacingt } \\
\text { Rate } 130\end{array}$ & 20250 & 0 & 44 & - & - & - & 14144 & 0 & 7 \\
\hline Control 3 & 8600 & 11 & 0 & - & - & - & 10656 & 13 & 0 \\
\hline
\end{tabular}

$\star H R \times \overrightarrow{\mathrm{BP}}$, heart rate per minute $\times$ mean arterial blood pressure, $\mathrm{mmHg}$.

†Pacing, right ventricular endocardial pacing.

\section{CASE 3}

A 24-year-old woman was admitted for investigation with a history, starting 1 year previously, of angina pectoris occurring on effort and more recently at rest. In addition, extrasystoles had been noted and there was nervousness. There had been no loss of weight. The thyroid gland was moderately enlarged. There were no abnormal features on examination of the cardiovascular system, nor was the heart enlarged on the chest $x$-ray film. The resting electrocardiogram showed minor nonspecific ST-T wave changes. Thyroid function tests revealed a $\mathrm{TT}_{4}$ of $11.1 \mu \mathrm{g} / 100 \mathrm{ml}(143 \mathrm{nmol} / \mathrm{l})$ and an FTI of $15.1 \mu \mathrm{g} / 100 \mathrm{ml}(194 \mathrm{nmol} / \mathrm{l})$ and the thyroid scan confirmed enlargement of the gland and revealed a 24-hour uptake of 76 per cent.

Cardiac catheterisation showed normal left and right sided pressures and a normal resting cardiac output. Biplane left ventriculography did not reveal any abnormalities. A lactate pacing study was performed, and showed no lactate production during control or with ventricular pacing to a rate of $150 \mathrm{a}$ minute. During ventricular pacing and a simultaneous intravenous infusion of phenylephrine, however, an abnormal response occurred with the production of 7 per cent lactate (Table).

Her thyrotoxicosis was brought under control by medical management and she has continued well since.

\section{Discussion}

Conditions causing cardiac pain typical of angina pectoris but not resulting from coronary arterial disease include cardiomyopathy (both obstructive and congestive), aortic valve disease (stenosis and regurgitation), and any form of severe left or right ventricular hypertrophy, including severe pulmonary hypertension. More recently, prolapse of the mitral valve has been recognised as a cause of cardiac pain as have both coronary arterial spasm and 'coronary steal' syndromes. The investigations in the 3 patients presented in this paper show that thyrotoxicosis can affect the myocardium. Under stress and in the absence of any coronary arterial obstruction an abnormal lactate response, with production rather than extraction, occurred suggesting myocardial hypoxia as the reason for the cardiac pain

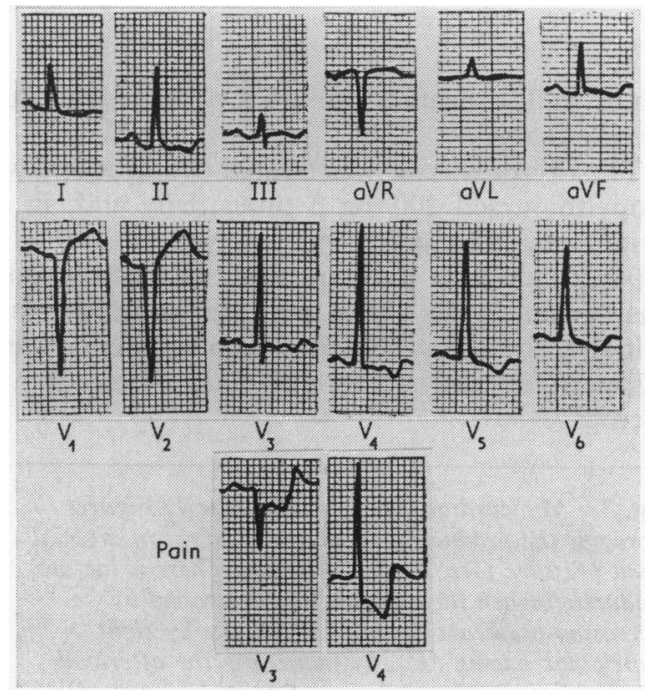

Fig. 4 Electrocardiogram, case 2. ST segment depression with inverted $T$ in many leads, $Q S$ pattern $V 1$ to 2. During an episode of typical cardiac pain occurring at rest, further $S T$ segment depression is recorded in leads V3 and 4. 
and other dramatic clinical abnormalities noted in all 3 patients.

In the presence of ischaemia resulting from coronary arterial disease abnormal myocardial metabolism is well recognised (Magee and Smith, 1935). Both during control and under stress, a normal myocardium consumes lactate in proportion to the arterial lactate concentration. An abnormally low lactate extraction or actual myocardial lactate production occurs in many patients with obstructive lesions of the coronary vessels indicating a change from aerobic to glycolytic metabolic pathways within the myocardial cells as a manifestation of deficient oxygen delivery to the myocardium.

That thyrotoxicosis causes important changes in the cardiovascular system has been known for many years and the evidence of a hyperkinetic circulation is often sought when considering its diagnosis. Whether thyrotoxicosis produces heart disease has been a matter of much debate (Willius et al., 1923; Lahy and Hamilton, 1924; Hurxthal, 1928; Magee and Smith, 1935; Friedberg and Sohval, 1937; Likoff and Levine, 1943; Griswold and Keating, 1949; Cookson, 1959). Summers and Surtees (1961) undertook a careful cardiovascular assessment of 200 unselected patients with thyrotoxicosis to determine the relation between the overactive thyroid gland and heart disease. They found that 30 per cent of the patients had a cardiac abnormality. The older the patient, the greater was the likelihood of cardiac disease being present. Those with definite ischaemic heart disease had the worst prognosis. Symons et al. (1971) reported 8 patients age 51 to 68 years who were observed from one to seven years and in whom a persistently raised proteinbound iodine indicated possible thyrotoxicosis which later became established. All 8 patients had evidence of cardiac disease, including rheumatic and non-rheumatic heart disease, and systemic hypertension, and 1 patient had myocardial ischaemia. The remaining 3 patients had paroxysmal or established atrial fibrillation. Cardiac catheterisation or coronary arteriography were not performed. Burstein et al. (1960) studied an unselected series of 384 thyrotoxic patients of whom 15 developed signs and symptoms of acute coronary insufficiency or myocardial infarction during the active stage of thyrotoxicosis. In 7, the diagnosis of myocardial infarction was confirmed. It is noteworthy that in this series the proportion of men to women with infarction was $2 \cdot 3: 1$, lower than usual and at least 2 of the patients were less than 40 years old. These authors concluded that the association of myocardial infarction and thyrotoxicosis resulted from the effects of the thyrotoxic state on coronary atherosclerosis which was already present. It is, however, important to note that in this study, too, no anatomical details of the coronary arteries of any of the affected patients were available.

In contrast, Duchosal and Henny (1941) reported a patient with thyrotoxicosis and angina pectoris who died shortly after thyroid surgery, and at necropsy the coronary arteries were normal. Similarly, Somerville and Levine (1950), in a study of 24 patients presenting with angina pectoris and thyrotoxicosis, reported that, in one, treatment of the thyrotoxicosis resulted in complete freedom from angina pectoris over the next 17 years of follow-up, suggesting that some process other than coronary arteriosclerosis was responsible for the angina pectoris.

Another effect of thyrotoxicosis on cardiac function has been documented by Campus et al. (1975) as heart block, which occurred in 2 patients, 1 of whom had had Adams-Stokes attacks. Both patients reverted to normal conduction when they became euthyroid.

In 1 of our 3 patients (case 1) an electrocardiographic pattern of acute infarction was associated with persistent elevation of the ST segment suggesting a ventricular aneurysm and this was confirmed by selective left ventriculography. No obstructive lesions were present in the epicardial coronary vessels on selective coronary arteriography but she was undoubtedly thyrotoxic as documented by the appropriate tests of thyroid function. That myocardial infarction may occur in patients with angiographically proven patent coronary vessels has been well documented (Likoff et al., 1962; Dear et al., 1971; Glancy et al., 1971). Recently, Eliot et al. (1974) performed necropsy studies in 10 patients who died with a typical clinical picture of acute myocardial infarction but in whom there was either none or only minimal coronary atherosclerosis, and suggested that the frequency of infarction without morphological evidence of acute occlusion and without the existence of severe coronary disease might be as high as 7 per cent. There was no mention of the thyroid state of their patients. It is perhaps important to note that atrial fibrillation was present in our patient and that the possibility exists that acute myocardial infarction leading subsequently to the development of a ventricular aneurysm was caused by coronary embolisation from a left atrial thrombus and that the coronary embolus subsequently recanalised leaving no trace on selective coronary arteriography.

The pathophysiology of the cardiac manifestations of hyperthyroidism has been reviewed by DeGroot (1972), DeGroot and Stanbury (1975), and by Levey (1975). An important manifestation is increased adrenergic activity which accounts for 
many of the classical symptoms of thyrotoxicosis as well as the known circulatory changes. Whether the adrenergic effects are secondary to an increased sensitivity to circulating catecholamine or to an actual increase in catecholamine at the receptor site has not yet been determined (Harrison, 1964; Waldstein, 1966; Levey, 1971), though it now seems likely that in the presence of thyrotoxicosis there remains normal sensitivity to circulating catecholamine. Thus, Wurtman et al. (1963) showed there was an increased concentration of free adrenaline and noradrenaline available for interaction with myocardial beta receptors though others have found an actual lowering of the concentration of circulating catecholamines in hypothyroidism (Christensen, 1972; Stoffer et al., 1973).

The physiological effects of excess thyroid hormone are well known but the basic mechanism of reaction of the thyroid hormone on the heart less so. It has been suggested (DeGroot, 1972) that one or more of the following may occur: (1) myocardial changes are secondary to an increased demand for a higher cardiac output resulting from the increased oxygen utilisation in the thyrotoxic state; (2) changes are a result of direct thyroxine action on mitochondrial high phosphate bond synthesis; (3) changes are a result of thyroxine induced increased synthesis of macromolecules of the cell and in the mitochondrion; (4) thyroxine acts by altering myocardial adenyl-cyclase; (5) the observed response is the result of an increased myocardial sensitivity to catecholamines.

Buccino et al. (1967) were able to show that thyroid hormone increased the speed of shortening of contractile elements without altering the total force production in an experimental animal model and that the positive inotropic response to noradrenaline varied inversely with the level of the thyroid hormone. Very similar changes were found by Gold and associates (1970) in skeletal muscle. Administration of thyroxine produces myocardial hypertrophy and a dramatic increase in the number of mitochondria (Zaimis et al., 1969), but whether this is a result of the primary effect of the hormone or a secondary mitochondrial response to high energy phosphate utilisation is not yet known (Hoch, 1966). More recently, attention has been directed to the stimulatory effect of thyroxine on adenylcyclase as an important mechanism of the myocardial effects of thyrotoxicosis (Levey and Epstein, 1969). It is indeed possible that the augmented myocardial contractility produced by the thyroid hormone or by catecholamines could be mediated by cyclic-AMP (Epstein et al., 1970). One could, therefore, suggest a hypothetical biochemical chain linking adrenaline, adenyl-cyclase, cyclic-AMP, and calcium ion to explain the positive inotropic effects of thyrotoxicosis. Even so, it is important to remember that hypothyroid animals have been reported to have normal amounts of myocardial adenyl-cyclase (Sobel et al., 1969), that myocardial adenyl-cyclase sensitivity to adrenaline is not increased in thyrotoxicosis, and that myocardial cyclic-AMP levels are not usually found to be augmented in thyrotoxic animal preparations (McNeill et al., 1969).

A further possible explanation of the effects of thyrotoxicosis on the heart was suggested by Challoner (1968), namely that the thyroid hormone may act by uncoupling oxidative phosphorylation in the myocardium.

Trying to summarise the evidence for the effects of thyroid hormone on the heart, DeGroot (1972) suggested that it caused both direct and indirect actions on cardiac function, probably mediated through changes in macromolecular synthesis in the nucleus or cytoplasm of the myocardial cell, rather than by a direct effect of the hormone on mitochondrial oxidative phosphorylation. Nevertheless, Ismail-Beigi and Edelman (1970) have already shown that there is an alteration of membrane ATP-ase after administering thyroxine and it is clear that much additional work needs to be done before the actual mechanism is known.

Whatever the basic mechanism is, the 3 patients presented in this paper show that thyrotoxicosis may, on occasion, be associated with typical angina pectoris and even the symptoms and electrocardiographic changes of impending or actual myocardial infarction. In 1 of the 3 patients, myocardial infarction did occur and was associated with left ventricular aneurysm. None of the 3 patients showed any evidence of coronary atherosclerosis, but in all, the myocardium produced lactate under stress, either during cardiac pacing or when the afterload was also raised by phenylephrine. On return to the control heart rate and blood pressure, myocardial lactate was no longer produced. Thus, there is clear evidence in all 3 patients that myocardial hypoxia could be produced by increasing the myocardial oxygen demand, indicating that there was difficulty in oxygen delivery, transport, and utilisation by the myocardial cell in the presence of thyrotoxicosis and in the absence of coronary atherosclerosis.

In 2 of the patients, the clinical picture was greatly improved after treatment of the thyrotoxicosis and with the establishment of a euthyroid state. Despite being euthyroid, however, 1 of the 3 patients (case 2) died suddenly and unexpectedly, indicating that the condition is not always benign.

On the basis of the 3 patients presented the 
following recommendations seem appropriate. Thyrotoxicosis should always be excluded when angina pectoris occurs, particularly in younger female patients. If thyrotoxicosis is present, a guarded prognosis should be given and continued medical follow-up advised after treatment even when no abnormalities of the coronary arteries have been shown by selective coronary arteriography.

\section{References}

Buccino, R. A., Spann, J. F., Jr., Pool, P. E., Sonnenblick, E. H., and Braunwald, E. (1967). Influence of the thyroid state on the intrinsic contactile properties and energy stores of the myocardium. Fournal of Clinical Investigation, 46, 1669-1682.

Burstein, J., Lamberg, B-A., and Erämaa, E. (1960). Myocardial infarction in thyrotoxicosis. Acta Medica Scandinavica, 166, 379-393.

Campus, S., Rappelli, A., Malvasi, A., and Satta, A. (1975). Heart block and hyperthyroidism. Archives of Internal Medicine, 135, 1091-1095.

Challoner, D. R. (1968). Evidence for uncoupled respiration in thyrotoxic and epinephrine-stimulated myocardium. American fournal of Physiology, 214, 365-369.

Christensen, N. J. (1972). Increased levels of plasma noradrenaline in hypothyroidism. Fournal of Clinical Endocrinology and Metabolism, 35, 359-363.

Cookson, H. (1959). The thyroid and the heart. British Medical fournal, 1, 254-259.

Dear, H. D., Russell, R. O., Jones, W. B., and Reeves, T. J. (1971). Myocardial infarction in the absence of coronary occlusion. American fournal of Cardiology, 28, 718-721.

DeGroot, L. J. (1972). Thyroid and the heart. Mayo Clinic Proceedings, 47, 864-871.

DeGroot, L. J., and Stanbury, J. B. (1975). The Thyroid and its Diseases, 4th ed. John Wiley, New York.

Duchosal, P. W., and Henny, G. (1941). Angine de poitrine et hyperthyroidisme. Cardiologia, 5, 372-387.

Eliot, R. S., Baroldi, G., and Leone, A. (1974). Necropsy studies in myocardial infarction with minimal or no coronary luminal reduction due to atherosclerosis. Circulation, 49, 1127-1131.

Epstein, S. E., Skelton, C. L., Levey, G. S., and Entman, M. (1970). Adenyl-cyclase and myocardial contractility. Annals of Internal Medicine, 72, 561-578.

Friedberg, C. H., and Sohval, A. R. (1937). The occurrence and the pathogenesis of cardiac hypertrophy in Graves' disease. American Heart fournal, 13, 599-618.

Glancy, D. L., Marcus, M. L., and Epstein, S. E. (1971). Myocardial infarction in young women with normal coronary arteriograms. Circulation, 44, 495-502.

Gold, H. K., Spann, J. F., Jr., and Braunwald, E. (1970). Effect of alterations in the thyroid state on the intrinsic contractile properties of isolated rat skeletal muscle. Fournal of Clinical Investigation, 49, 849-854.

Griswold, D., and Keating, J. H., Jr. (1949). Cardiac dysfunction in hyperthyroidism: a study of 810 cases. American Heart fournal, 38, 813-822.

Harrison, T. S. (1964). Adrenal medullary and thyroid relationships. Physiological Reviews, 44, 161-185.

Hoch, F. L. (1966). Rapid effects of a subcalorigenic dose of L-thyroxine on mitochondria. fournal of Biological Chemistry, 241, 524-525.

Hurxthal, L. M. (1928). Heart failure and hyperthyroidism. American Heart fournal, 4, 103-108.
Ismail-Beigi, F., and Edelman, I. S. (1970). Mechanism o thyroid calorigenesis: role of active sodium transport. Proceedings of the National Academy of Sciences of the United States of America, 67, 1071-1078.

Judkins, M. P. (1967). Selective coronary arteriography. Part I. A percutaneous transfemoral technic. Radiology, 89, 815-824.

Lahy, F. H., and Hamilton, B. E. (1924). Thyrocardiacs: their diagnostic difficulties: their surgical treatment. Surgery, Gynecology and Obstetrics, 39, 10-14.

Levey, G. S. (1971). Catecholamine sensitivity, thyroid hormone and the heart. American fournal of Medicine, 50, 413-420.

Levey, G. S. (1975). The heart and hyperthyroidism. Use of beta-adrenergic blocking drugs. Medical Clinics of North America, 59, 1193-1201.

Levey, G. S., and Epstein, S. E. (1969). Myocardial adenyl cyclase: activation by thyroid hormones and evidence for two adenyl cyclase systems. Fournal of Clinical Investigation, 48, 1663-1669.

Likoff, W. B., and Levine, S. A. (1943). Thyrotoxicosis as the sole cause of heart failure. American fournal of the Medical Sciences, 206, 425-434.

Likoff, W., Segal, B., and Dreifus, L. (1962). Myocardial infarction patterns in young subjects with normal coronary arteriograms. Circulation, 26, 373-378.

McNeill, J. H., Muschek, L. D., and Brody, T. M. (1969). The effect of tri-iodothyronine on cyclic AMP, phosphorylase, and adenyl cyclase in rat heart. Canadian fournal of Physiology and Pharmacology, 47, 913-916.

Magee, H. R., and Smith, H. L. (1935). Auricular fibrillation in hyperthyroidism. The influence of age. American Fournal of the Medical Sciences, 189, 683-690.

Sobel, B. E., Dempsey, P. J., and Cooper, T. (1969). Normal myocardial adenyl cyclase activity in hyperthyroid cats. Proceedings of the Society for Experimental Biology and Medicine, 132, 6-9.

Somerville, W., and Levine, S. A. (1950). Angina pectoris and thyrotoxicosis. British Heart fournal, 12, 245-257.

Stoffer, S. S., Jiang, N-S., Gorman, C. A., and Pikler, G. M. (1973). Plasma catecholamines in hypothyroidism and hyperthyroidism. Fournal of Clinical Endocrinology and Metabolism, 36, 587-589.

Summers, V. K., and Surtees, S. J. (1961). Thyrotoxicosis and heart disease. Acta Medica Scandinavica, 169, 661-671.

Symons, C., Richardson, P. J., and Wood, J. B. (1971). Unusual presentation of thyrocardiac disease. Lancet, 2, 1163-1167.

Vaughan, C. W., and Galloway, R. E. (1964). A convenient deproteinizing procedure in the enzymatic determination of lactate and pyruvate in whole blood (abstract). Alabama fournal of Medical Sciences, 1, 104-107.

Waldstein, S. S. (1966). Thyroid-catecholamine interrelations. Annual Review of Medicine, 17, 123-132.

Willius, F. A., Boothby, W. M., and Wilson, L. B. (1923). The heart in exophthalmic goiter and adenoma with hyperthyroidism. Medical Clinics of North America, 7, 189-219.

Wurtman, R. J., Kopin, I. J., and Axelrod, J. (1963). Thyroid function and the cardiac disposition of catecholamines. Endrocrinology, 73, 63-74.

Zaimis, E., Papadaki, L., Ash, A. S. F., Larbi, E., Kakari, S., Matthew, M., and Paradelis, A. (1969). Cardiovascular effects of thyroxine. Cardiovascular Research, 3, 118-133.

Requests for reprints to Dr. Leon Resnekov, Hospital Box 423, The University of Chicago Medical Center, 950 East 59th Street, Chicago, Illinois 60637, U.S.A. 